\title{
The changing scenario of pattern of peripartum hysterectomy: prevention and preparedness matters
}

\author{
Sasirekha Rengaraj*, Saranya Rajamanickam, Sutharsika Thiyagalingam
}

Department of Obstetrics and Gynaecology, JIPMER, Puducherry, India

Received: 23 December 2021

Accepted: 13 January 2022

\author{
*Correspondence: \\ Dr. Sasirekha Rengaraj, \\ E-mail: drsasirekha.r_ms@ymail.com
}

Copyright: () the author(s), publisher and licensee Medip Academy. This is an open-access article distributed under the terms of the Creative Commons Attribution Non-Commercial License, which permits unrestricted non-commercial use, distribution, and reproduction in any medium, provided the original work is properly cited.

\begin{abstract}
Background: Peripartum hysterectomy is a life-saving procedure, often associated with significant morbidity. The indication for peripartum hysterectomy has been shifted from PPH and rupture uterus to placental abnormalities and haemorrhage. Reducing the number of caesarean sections is the major step towards minimizing the chance of undergoing peripartum hysterectomy in subsequent pregnancy at the same time the morbidity is more if the peripartum hysterectomy is a on table decision.

Methods: This was a descriptive study from a tertiary care centre, South India and all the case records of women who underwent peripartum hysterectomy were reviewed from 2012 to 2017 . All the details including demographic details, clinical characteristics, indications and clinical outcome of those women were recorded. The data was analyzed using SPSS version 20.

Results: The incidence of peripartum hysterectomy was $0.7 / 1000$ deliveries and it was $0.24 \%$ and $0.03 \%$ after caesarean section and vaginal deliveries respectively. The placental abnormalities $(46.2 \%)$ were the commonest cause followed by uterine atony $(28.8 \%)$ and rupture uterus $(21.2 \%)$. It was total hysterectomy in all of them except 2 women who underwent subtotal hysterectomy $(3.8 \%)$ and the commonest visceral injury was bladder $(15.4 \%)$. The maternal mortality rate was $9.8 \%$ and $61.5 \%(n=32)$ received massive blood transfusions.

Conclusions: Even though a life-saving procedure, the timing and the preoperative hemodynamic status of the women were the major determinants of adverse outcome associated with peripartum hysterectomy. Preoperative planning and risk stratification models are essential to minimize the risk of undergoing hysterectomy and to reduce the morbidity associated with the procedure.
\end{abstract}

Keywords: Peripartum hysterectomy, Placenta praevia, Placenta accreta

\section{INTRODUCTION}

Peripartum hysterectomy $(\mathrm{PH})$, surgical removal of the uterus around the time of delivery either during or in the immediate postpartum period usually within 24 hours, is a life-saving procedure. It is associated with severe maternal morbidity and mortality and considered as a near-miss event in obstetrics. In recent times, there is a shift in the cause for $\mathrm{PH}$ from rupture uterus and sepsis to morbidly adherent placenta (MAP). ${ }^{1-4}$ Several studies have shown that the risk factors, causes and maternal outcome of PH differ throughout the world. ${ }^{1,4,5}$ It is usually reserved for situations when there is intractable haemorrhage and the outcome depends on factors like transfusion facilities, surgical skill and postoperative care. Most of the times it is unplanned and decided on the table and the decision to perform $\mathrm{PH}$ is challenging. There is an increased risk of maternal death, haemorrhage, sepsis, massive transfusion, intraoperative complications and postoperative morbidity and the rate of morbidity is more in developing countries., ${ }^{2,6,7}$ The incidence of $\mathrm{PH}$ ranging from 0.6 to 2.28 per 1000 births 
with the mortality of $0.29-0.94$ per 100,000 deliveries. The global rise in caesarean section has increased the risk of undergoing $\mathrm{PH}$ due to both rupture uterus and placental abnormalities. ${ }^{1,8,9}$ The objective of the study was to estimate the incidence and causes of PH in modern obstetrics from a tertiary center, South India and analyze the outcome of the procedure in terms of maternal morbidity and mortality.

\section{METHODS}

This was a descriptive study of 46 cases of $\mathrm{PH}$ performed at JIPMER, a tertiary care center from South India. Medical records of all women who had undergone $\mathrm{PH}$ from January 2012 to December 2017 were analyzed retrospectively. Data was collected regarding maternal characteristics like age, parity, past obstetric history, details of current pregnancy and labor, mode of delivery, indications for $\mathrm{PH}$, blood loss, blood transfusion and associated maternal morbidity and mortality. All peripartum hysterectomies were performed by a consultant who is an expert in managing obstetric emergencies and the decision to perform $\mathrm{PH}$ was taken by senior consultants. All the quantitative variables were expressed as mean \pm standard deviation and the qualitative variables were expressed as frequencies and percentages, $\mathrm{p}<0.05$ considered significant. The data was analysed by using SPSS version 20.

\section{RESULTS}

There were 72,486 deliveries happened during the study period of which $13,047 \quad(17.9 \%)$ were caesarean deliveries and 59,439 (82.1\%) were vaginal deliveries. A total of 52 peripartum hysterectomies were performed which gives the incidence of $0.7 / 1000$ deliveries. The incidence of peripartum hysterectomies after vaginal and caesarean deliveries were $0.03 \%$ (30/100000 deliveries) and $0.24 \%$ (240/100000 deliveries) respectively.

The mean age of the women was $28.5 \pm 3.2$ (range: 18-38) years and $13.5 \%(\mathrm{~N}=7)$ were $>35$ years. The mean parity was $2.4 \pm 1.8$ (range: $0-5)$ and $36.5 \%(\mathrm{~N}=19)$ were parity of 3 and above. A total of 12 women $(23.1 \%)$ were $>75 \mathrm{~kg}$ and the mean weight of the women was $62.8 \pm 12.4$ (4892) $\mathrm{kgs}$ (Table 1). Two of them had severe postpartum haemorrhage, one of them had precipitated labor followed by PPH and the other one delivered outside and had severe PPH. There was a patient with failed instrumentation subsequently had rupture uterus. Two of them had uterine surgery in the past in the form of myomectomy and septal resection also had rupture uterus. There was a case of acute fatty liver of pregnancy who underwent caesarean section ended up with $\mathrm{PH}$. There was a case of dengue with severe thrombocytopenia, after vaginal delivery that had postpartum collapse and PPH. This was resistant to medical management and $\mathrm{PH}$ was done at the end. Postpartum haemorrhage and rupture uterus were the indications for $\mathrm{PH}$ in their first pregnancy.
The mean gestational age was $36.4 \pm 3.2$ (range 26-41) weeks (Table 1). Of the 2 women $(3.8 \%)$ were less than 28 weeks, one had rupture uterus following misoprostol use at 28 weeks and the other woman presented with massive hemoperitoneum due to placenta percreta at 26 weeks. Almost half of the women $(50 \%)$ had a history of prior uterine surgery and 24 women $(46.2 \%)$ had a caesarean section in the previous pregnancy with the mean of $1.4 \pm 0.8$ (Table 1 ).

Table 1: Maternal characteristics of women underwent peripartum hysterectomy $(n=52)$.

\begin{tabular}{|lll|}
\hline Variable & Mean \pm SD & Range \\
\hline Age (years) & $28.5 \pm 3.2$ & $18-38$ \\
\hline Parity & $2.4 \pm 1.8$ & $0-5$ \\
\hline Maternal weight (kg) & $62.8 \pm 12.4$ & $48-92$ \\
\hline Gestational age (weeks) & $36.4 \pm 3.2$ & $26-41$ \\
\hline $\begin{array}{l}\text { Previous obstetric } \\
\text { complications }\end{array}$ & $\mathbf{N}$ & $\%$ \\
\hline H/O abortion & 4 & 7.7 \\
\hline H/O ectopic pregnancy & 2 & 3.8 \\
\hline Previous caesarean section & 24 & 46.2 \\
\hline Previous myomectomy & 1 & 1.9 \\
\hline $\begin{array}{l}\text { Previous hysteroscopic } \\
\text { septal resection }\end{array}$ & 1 & 1.9 \\
\hline Anemia & 30 & 57.7 \\
\hline
\end{tabular}

The most common indication for peripartum hysterectomy was placental abnormalities, 24 (46.2\%) followed by uterine atony $(28.8 \%)$ and rupture uterus $(21.2 \%)$. Of the 24 women who had placental abnormalities 4 women (16.7\%) had placenta praevia and the rest of them had morbidly adherent placenta $(83.3 \%)$. The peripartum hysterectomy was on table, decision in 12 $(60 \%)$ of them who had morbidly adherent placenta and in only 8 of them $(40 \%)$ the diagnosis was established preoperatively (Table 2 ).

Table 2: Indications for peripartum hysterectomy $(\mathrm{n}=52)$.

\begin{tabular}{|c|c|c|}
\hline Indications & $\mathbf{N}$ & $\%$ \\
\hline Placental abnormalities & 24 & 46.2 \\
\hline Uterine atony & 15 & 28.8 \\
\hline Rupture uterus & 11 & 21.2 \\
\hline Traumatic PPH (hematoma) & 02 & 03.8 \\
\hline
\end{tabular}

Subtotal hysterectomy was performed in only two women $(3.8 \%)$ and the rest of them underwent total hysterectomy. Additional surgical procedures like compressive sutures (12 women, $23.1 \%$ ) and B/L internal iliac artery ligation (16 women, $30.1 \%$ ) were done before resorting to $\mathrm{PH}$. Uterine packing was done in 14 women (26.9\%). Re exploration was needed in four women of which three happened within 4 hours of $\mathrm{PH}$ and the other one 12 hours postoperative. While the majority of them required multiple transfusions the mean packed cell, platelet and FFPs were 4, 3 and 6 units respectively. 
There were five maternal deaths and three near miss deaths. Since three patients were referred on inotropes and they were in an irreversible state of shock by the time laparotomy was undertaken, early referral and referral with appropriate measures (like an anti shock garment) probably would have changed the outcome. All the women underwent total hysterectomy except two women who were hemodynamically unstable in spite of appropriate measures and underwent subtotal hysterectomy. The common indications were placental abnormalities, rupture uterus and cervical tear/ broad ligament hematoma in the present study was the reason for the high incidence of total hysterectomy.

Table 3: Outcome of women underwent peripartum hysterectomy $(n=52)$.

\begin{tabular}{|lll|}
\hline Variable & N/Mean \pm SD & \%/range \\
\hline Blood loss $(\mathbf{m l})$ & $2950 \pm 1260$ & $1800-4200$ \\
\hline Blood transfused & $4.8 \pm 2.8$ & $2-24$ \\
\hline Hospital stay (days) & $14.5 \pm 8.4$ & $8-68$ \\
\hline Massive PPH & 32 & 61.5 \\
\hline Inotropic support & 23 & 44.2 \\
\hline Bladder injury & 08 & 15.4 \\
\hline Ventilatory support & 06 & 11.5 \\
\hline Maternal death & 5 & 9.6 \\
\hline
\end{tabular}

The frequency and types of complications are given in (Table 4). A total of 32 (61.5\%) women had blood loss of $>2,500 \mathrm{ml}$ with mean estimated blood loss of $2950 \pm 1260$ (range 1800-4200) ml. Eighteen (34.6\%) of them had undergone $\mathrm{B} / \mathrm{L}$ internal iliac artery ligation and or compressive sutures in addition to hysterectomy. All women received a blood transfusion with an average unit of packed cell transfusion was 4.8 units (range 2-24). Overall, these 52 women received 350 packed cells, 480 FFPs, 180 platelets and 72 cryoprecipitates. Inotropic support was needed in $23(44.2 \%)$ women and $6(11.5 \%)$ of them were on ventilator for $>24$ hours. The most common visceral injury was bladder injury seen in 8 $(15.4 \%)$ women. There were 4 laparotomies of which two women had undergone hysterectomy outside for haemorrhage after vaginal delivery and referred in view of persistent hypotension. There was no active bleeding, uterine packing was done in one woman and in another woman internal iliac artery ligation was done. There were 5 maternal deaths $(9.6 \%)$ of which three of them were referred on inotropes (Table 3). One woman had bleeding placenta percreta with massive hemoperitoneum who presented at 26 weeks and in spite of all the necessary efforts patient could not be revived. The other woman had massive post-partum haemorrhage (PPH) following precipitated delivery who also succumbed to death in spite of best effort. All of them had died within 72 hours except one woman who was discharged in a vegetative state after 68 days of hospital stay and subsequently succumbed at home. The mean duration of hospital stay was 14.5 (range 8-68). It was a near miss death in 6 of them of which three women had intractable PPH following vaginal delivery and one woman had postpartum collapse following vaginal birth after caesarean section (VBAC) and the other woman presented with bleeding placenta praevia at 34 weeks who had cardiac arrest on table. The three main risk factors identified to be associated with peripartum hysterectomy in the study were multiparIty $(63.5 \%)$, placental abnormalities $(46.2 \%)$ and h/o prior caesarean section $(46.2 \%)$.

Table 4: Comparison of maternal parameters after elective and emergency peripartum hysterectomy in women with adherent placenta.

\begin{tabular}{|llll|}
\hline Variable & $\begin{array}{l}\text { Elective } \\
\text { peripartum } \\
\text { hysterectomy } \\
(\mathbf{N}=\mathbf{8})\end{array}$ & $\begin{array}{l}\text { Emergency } \\
\text { peripartum } \\
\text { hysterectom } \\
\mathbf{y}(\mathbf{N}=12)\end{array}$ & $\begin{array}{l}\text { P } \\
\text { value }\end{array}$ \\
\hline Age & $28(18-34)$ & $27(18-36)$ & 0.31 \\
\hline Parity & $2(1-4)$ & $2(1-3)$ & 0.46 \\
\hline Hemoglobin & $10.8 \pm 1.2$ & $8.2 \pm 2.8$ & 0.01 \\
\hline $\begin{array}{l}\text { H/O } \\
\text { caesarean } \\
\text { section }\end{array}$ & 5 & 10 & 0.29 \\
\hline $\begin{array}{l}\text { USG } \\
\text { diagnosis }\end{array}$ & 7 & 6 & 0.08 \\
\hline $\begin{array}{l}\text { Preoperative } \\
\text { MRI }\end{array}$ & 6 & 2 & 0.01 \\
\hline $\begin{array}{l}\text { Mean blood } \\
\text { loss }\end{array}$ & $1862.5 \pm 570.6$ & $2513.3 \pm 325.7$ & 0.00 \\
\hline $\begin{array}{l}\text { Inotropic } \\
\text { support }\end{array}$ & 2 & 8 & 0.06 \\
\hline $\begin{array}{l}\text { Post OP } \\
\text { Ventilatory } \\
\text { Support }\end{array}$ & 2 & 6 & 0.49 \\
\hline $\begin{array}{l}\text { Bladder } \\
\text { injury }\end{array}$ & 1 & 6 & 0.08 \\
\hline $\begin{array}{l}\text { Wound } \\
\text { infection }\end{array}$ & 1 & 6 & 0.32 \\
\hline Death & 0 & 6 & 0.08 \\
\hline
\end{tabular}

The comparison of factors among women who underwent elective vs. emergency $\mathrm{PH}$ for placental causes is depicted in (Table 4). The preoperative USG diagnosis was present only in $50 \%$ of women who had emergency hysterectomy compared to $87.5 \%$ of who underwent elective PH $(\mathrm{p}=0.08)$. The mean haemoglobin and mean blood loss were significantly more in the emergency $\mathrm{PH}$ group compared to elective $\mathrm{PH}$. The need for inotropic support, visceral injury and postoperative ventilatory support were also more in the emergency $\mathrm{PH}$ group although the difference was not significant.

\section{DISCUSSION}

The first successful caesarean hysterectomy was done by Porro of Milan since then it's an important lifesaving procedure in obstetrics. The incidence of $\mathrm{PH}$ in the present study was $0.7 / 1000$ deliveries, which are similar to developed countries. This is very different from other 
studies of South Asia and Africa, which constitutes a major portion of maternal death. ${ }^{4,10}$ Some of the tertiary centers from India have almost similar rates of $\mathrm{PH}$ ranges from $0.7-0.8 / 1000$ deliveries. Contemporary evidence has shown that the incidence of $\mathrm{PH}$ has changed over the decades, from rupture uterus due to obstructed labor to rupture uterus due to scarred uterus and, atonic postpartum haemorrhage to abnormal placentation. A systematic review on peripartum hysterectomy of Van Den Akker et al had shown the varied incidence of peripartum hysterectomy across worldwide. Overall the incidence was $1 / 1000$ deliveries and it varies from $2.8 / 1000$ deliveries in developing countries to $0.7 / 1000$ deliveries in developed countries. ${ }^{1}$ An Indian study by Sharma et al had documented the high rate of $6.9 / 1000$ deliveries from North India over one year period. Referral centre was the sole reason explained in their literature and the placental causes contributed for the majority of peripartum hysterectomies $(60 \%) .^{3}$ The incidence of PH was lowest in Ireland $(0.32 / 1000$ deliveries) and highest in Pakistan $(11 \%)$ in a time trend analysis of $\mathrm{PH}{ }^{4}$

The frequency of $\mathrm{PH}$ was more common in women of $>30$ years and multiparous women in the majority of the studies. However, in the present study, $48.1 \%$ of women were $>30$ years and $63.4 \%$ of women were multiparous. There were 7 women $(13.5 \%)$ who had $\mathrm{PH}$ in their first pregnancy. Of these 7 women who were primigravidae in the present study, there were two maternal deaths. Even though the risk of undergoing $\mathrm{PH}$ is more in multiparous women, nulliparous women should not be taken lightly, thorough history and risk assessment should be done. Moreover, good antenatal care and optimizing the haemoglobin status before delivery play a major role in prevention of PPH. Various studies identified advanced maternal age and increasing parity as independent risk factors for PH. The risk of undergoing $\mathrm{PH}$ was 1.4 times more in high parity and 6.6 times more in elder women. The maternal mean age among women who underwent PH was statistically different in two different periods (2009-13 and 2013-18) and it was more in the period II $(36.9 \pm 4.7$ vs. $38.9 \pm 5.9$ years, $p=0.035){ }^{4}$

The most frequent indication for $\mathrm{PH}$ in the present study was placental abnormalities in $46.2 \%$, followed by uterine atony in $28.8 \%$ of cases. These findings are similar to findings from developed countries. The global rise in caesarean section rate has contributed to this changing scenario. However, postpartum haemorrhage is the leading cause of $\mathrm{PH}$ in most of the developing countries. The changing trend in the present study is consistent with existing evidence from the literature. Uterine scarring which occurs either due to caesarean section or curettage in previous pregnancy increase the risk of placental abnormalities. Apart from placental abnormalities, the risk of undergoing $\mathrm{PH}$ is more in women with previous caesarean section because of rupture uterus. Cromi et al reviewed potential risk factor for $\mathrm{PH}$ and he found the risk of undergoing $\mathrm{PH}$ after one caesarean section was 6.72 times (95\% CI 2.99-15.09) and the risk increases with the number of caesarean sections. The risk is even higher after myomectomy also (OR 24.5 95\% CI 6.7-90.2)..$^{11}$

The incidence of $\mathrm{PH}$ in the present study among women who delivered vaginally was 30/100,000 deliveries and it was 240/100,000 in caesarean deliveries. The majority of the studies have shown a similar picture across the world. Apart from placental abnormalities, the risk of rupture uterus is also more in women with previous caesarean section. Moreover the readiness of the uterus for hysterectomy in case of PPH is more during caesarean section than a vaginal delivery might also be the reason for the increased incidence of $\mathrm{PH}$ in women with caesarean section. Not only previous CS but also caesarean in current pregnancy is a high risk factor for undergoing $\mathrm{PH}$. Uysal et al found the rate of $\mathrm{PH}$ was 93.6\% after caesarean section compared to $6.4 \%$ after vaginal delivery. ${ }^{7}$ The odds of undergoing $\mathrm{PH}$ was 11.4 times higher during caesarean section. ${ }^{1}$

Many studies from developing countries have shown there is increased rates of subtotal PH $(87.7 \%)$ than total $\mathrm{PH}$ because the most common indication used to be atonic $\mathrm{PPH}$, which requires rapid, simple and safe procedure in the majority of the placental abnormalities, the most common cause in developed countries necessitates total $\mathrm{PH}$ as it was in the present study. ${ }^{3,7}$

The maternal morbidity associated with $\mathrm{PH}$ is generally high and is mainly due to increased blood loss, bladder injury, ventilatory support, sepsis and increased risk of laparotomy. The maternal mortality of the present study was $9.6 \%$, which is much higher than the reports from developed country ( 0 to $4.5 \%$ ). As already discussed three of five maternal deaths had delivered outside and referred in an unstable state. Overall effective blood transfusion facilities, good antenatal care, active management of third stage of labour, appropriate utilization of medical measures and conservative surgeries like uterine packing, tamponade, compressive sutures and devascularisation techniques have minimized the number of $\mathrm{PH}$ due to haemorrhage and improved the survival in women with PPH. The most common morbidity was febrile morbidity $(19.2 \%)$ followed by bladder injury $(15.4 \%)$ in the present study. The morbidity pattern was similar to other studies in

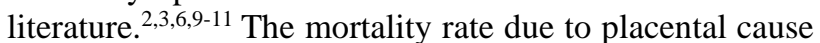
was $4.2 \%(1 / 24)$ when compared to post-partum haemorrhage $(14.3 \%, n=4 / 28)$. The maternal condition was unstable at the time of peripartum hysterectomy in all these four women and three of them delivered elsewhere and referred late on inotropes.

The morbidity observed in women undergoing $\mathrm{PH}$ is not determined due to surgery alone, but to the underlying indications for which it is undertaken, the timing of the decision to proceed for $\mathrm{PH}$ and hemodynamic status of the women. The long term morbidity associated with PH 
and massive blood loss has not been studied. The risk of febrile morbidity was more in emergency $\mathrm{PH}(10 \%)$ compared to elective $\mathrm{PH}(0 \%)$. However, a detailed analysis of outcome between emergency and elective $\mathrm{PH}$ due to all causes could not be done.

Advanced maternal age, parity and previous caesarean section were found to be the important risk factors associated with PH. Even pregnancies following assisted reproductive technologies (ART) were found to be associated with PH (OR 5.9 95\% CI 2.2-16.4) and ART pregnancies should be incorporated into risk stratification models for obstetric haemorrhage. ${ }^{11}$ Protocol based effective management of high risk pregnancies and risk stratification for $\mathrm{PH}$ is essential to minimize the risk of undergoing $\mathrm{PH}$ and the morbidity associated with it. Previous uterine surgery being the important cause of placental abnormalities it is prudent to diagnose it in the antenatal period and plan the surgery in advance with adequate precautions. Arranging blood and blood products, multidisciplinary management involving intervention radiologists and anaesthesiologists early would help in minimizing the morbidities associated with $\mathrm{PH}$. Research on innovations and improvements in the conservative surgical approach for managing adherent placenta might help to conserve the uterus in near future.

\section{CONCLUSION}

Placental abnormalities are the most common cause for peripartum hysterectomy in the recent days, which supports the hazard of rising caesarean section. The haemorrhage has become the rare cause of $\mathrm{PH}$ even in developing countries; however previous caesarean section and multiparity increase the risk of undergoing peripartum hysterectomy to a greater extent. Effective transfusion facilities are the cornerstone in the management of Obstetric haemorrhage, which will improve the survival and lessen the morbidity. Curtailing the number of primary caesarean section by appropriate auditing and utilization of conservative surgical methods for $\mathrm{PPH}$ will minimize the risk of undergoing $\mathrm{PH}$. Establishing the diagnosis in the antenatal period and multidisciplinary protocol based management will reduce the morbidity associated with the procedures as well.

\section{Funding: No funding sources}

Conflict of interest: None declared

Ethical approval: The study was approved by the Institutional Ethics Committee

\section{REFERENCES}

1. Van Den Akker T, Brobbel C, Dekkers OM, Bloemenkamp KW. Prevalence, indications, risk indicators, and outcomes of emergency peripartum hysterectomy worldwide. Obstet Gynecol. 2016; 128(6):1281-94.

2. D'Arpe S, Franceschetti S, Corosu R, Palaia I, Di Donato V, Perniola $G$ et al Emergency peripartum hysterectomy in a tertiary teaching hospital: a 14-year review. Arch Gynecol Obstet. 2015;291(4):841-7.

3. Sharma B, Sikka P, Jain V, Jain K, Bagga R, Suri V. Peripartum hysterectomy in a tertiary care hospital: epidemiology and outcomes. Journal of anaesthesiology, clinical pharmacology. 2017;33(3): 324.

4. Triunfo S, Ferrazzani S, Volpe M, Scambia G, Lanzone A. Old and novel insights into emergency peripartum hysterectomy: a time-trend analysis. Arch Gynecol Obstet. 2020;1-7.

5. Kallianidis AF, Maraschini A, Danis J, Colmorn LB, Deneux-Tharaux C, Donati S, et al Epidemiological analysis of peripartum hysterectomy across 9 European countries. Acta Obstet Gynecol Scand. 2020.

6. Pandey K, Agrawal S, Gupta R, Gupta G. A review of cases of peripartum hysterectomy: five year experience at tertiary care centre in North India. Indian Obstet Gynecol. 2020;10(1):54-9.

7. Uysal D, Cokmez H, Aydin C, Ciftpinar T. Emergency peripartum hysterectomy: A retrospective study in a tertiary care hospital in Turkey from 2007 to 2015. JPMA. 2018;68(3):487-9.

8. Tamrakar R, Pandit U, Shrestha S, Sharma B, Joshi R. Peripartum hysterectomy and its risk factors. J Chitwan Med Coll. 2019;9(1):27-31.

9. Stepp K. Emergency Peripartum Hysterectomy. J Gynecol Obstet Neonat Nurs. 2019;48(3):S158-9.

10. Saha JK, Mistri PK, Sinha N. Critical Evaluation of Emergency Peripartum Hysterectomy Cases in a Tertiary Care Centre in Eastern India. J Evol Med Dent Sci. 2019;8(46):3422-7.

11. Cromi A, Candeloro I, Marconi N, Casarin J, Serati M, Agosti M, et al . Risk of peripartum hysterectomy in births after assisted reproductive technology. Fertil Steril. 2016;106(3):623-8

12. Jónasdóttir E, Aabakke AJ, Colmorn LB, Jakobsson M, Äyräs O, Baghestan E, et al. Lessons learnt from anonymized review of cases of peripartum hysterectomy by international experts: A qualitative pilot study. Acta Obstet Gynecol Scand. 2019;98(8): 955-7.

Cite this article as: Rengaraj S, Rajamanickkam S, Thiyagalingam $\mathrm{S}$. The changing scenario of pattern of peripartum hysterectomy: prevention and preparedness matters. Int J Reprod Contracept Obstet Gynecol 2022:11:568-72. 